\title{
Trade Integration in Colombia: A Dynamic General Equi- librium Study with New Exporter Dynamics
}

George Alessandria ${ }^{1}$

University of Rochester and NBER

Oscar Avila

University of Rochester

First Draft: November 2016

\section{Preliminary - Do not cite without permission}

\begin{abstract}
We study trade integration in Colombia over a long period through the lens of GE model with new exporter dynamics in which exporters invest in accumulating a better shipping technology. We emphasize the relationship between the firm-level export intensity and aggregate export intensity disciplines the changes in technology and policy accounting for this integration. We find that a common decline in tariffs can account for about 75 percent of the growth in exports as a share of manufacturing sales. We attribute the remaining 25 percent to an increase in the success of investments in export market access. We show that about 10 percent of the increase is accounted for through the endogenous accumulation of an improved exporting technology by existing exporters.
\end{abstract}

\section{Introduction}

We study Colombia's trade integration from 1981 to 2013. In this period, the Colombian manufacturing sector went from being relatively closed, exporting only 5.5 percent of its shipments in 1981 and 1982 , to being substantially more open, exporting almost 15 percent of its shipments in 2006 and 2007. This tripling of manufacturing exports involved a substantial change in the involvement of producers in trade and followed a range of policy reforms from changes in licensing, tariffs, taxes, subsidies, and more. Our primary goal is

\footnotetext{
${ }^{1}$ George.Alessandria@gmail.com; oscar.avila03@gmail.com. We thank Marcela Eslava for helpful comments.
} 
to identify the key the changes in technology and policy that generated this expansion in trade. Our secondary goal is to see how trade and trade integration has changed measures of misallocation in Colombia.

To organize our analysis, we examine Colombia's integration through the lens of a dynamic general equilibrium with heterogeneous firms that make forward looking investments in export market access. In particular, we use the new exporter model of Alessandria, Choi, and Ruhl (2014) to study the source Colombian trade integration. This model has a flexible specification of the exporting technology that can capture the salient features of firm lifecycle and growth in the export market recently emphasized in the literature (add references). In particular, it captures the tendency for new exporters to be relatively small, export a small share of output, and be relatively likely to exit.

The first question we ask is: What was the technology for exporting in Colombia like at the start of the trade liberalization? This hinges on the assumptions of our model. We follow the literature and have firms make investments in export market access. Specifically, firms incur a sunk cost to start exporting and a different fixed cost to continue exporting. Additionally, these investments bear some risk in the sense that the investment in market access has an uncertain return. Specifically, the variable cost of shipping a good is uncertain and firm-specific. Over time, with sustained export market participation, we also find that the shipping technology improves. This introduces an endogenous component to the export intensity of an exporter and implies a long period of investment in building export sales.

We estimate the nature of this technology for Colombian firms. We find that the upfront sunk cost to start exporting is quite low, only about 60 percent of the cost of staying in the market. In contrast, in a study of a subset of Colombian firms in three sectors over the same period, Das, Roberts, and Tybout (2007) find the up-front entry cost is nearly 10 times the cost of continuing in the export market. We also find that this investment is quite risky as it only yields exports about 15 percent of the time and that these new exporters use 
a technology that is about 9 times worse than the most efficient exporters. We also find that inefficient exporters have about an 8 percent chance of improving their exporting technology per year. In this way, we see that the typical new exporter expects it to take 5 to 10 years before it becomes as efficient an exporter as the typical continuing exporter.

The next question we ask is whether our dynamic model of endogenous export participation calibrated to the early Colombian economy can capture the changes in the level of exports and distribution of exports from a single policy change, which we model as a change in the tariff. Perhaps surprisingly, given the various policy tools discussed and enacted in Colombia, we find that moving the economy from a 10 percent tariff to zero percent tariff captures the 75 percent of the overall change in exports and is constistent with the change in firm-level export intensity observed. That is, our model predicts the average export intensity among exporters, what we call the micro export intensity, will rise by about 46.9 percent while in the data the increase was about 45.2 percent. Our model also captures the aggregate change quite well as exports over total sales, what we call the macro export intensity, are predicted to grow by 74.3 percent while in practice the increase was closer to 95.5 percent. We use the model to decompose the change in the micro export intensity into a part from the policy change and a part due to exporters accumulating a better exporting technology. We find the investments in a better exporting technology magnify the micro export intensity by about 20 percent.

We then ask what other changes in the exporting technology could account for the gap between our model and the data on aggregate export flows. Here, we consider a variety of changes to the fixed trade costs and trade cost uncertainty. To generate the same macro export intensity while remaining consistent with the micro export intensity and the level of churning in the export market requires an improvement in the returns to investments in export market access by non-exporters. Specifically, we find that in the latter period 25 percent of investments in export market access yield exports compared to 15 percent in the 
earlier period.

We then ask whether our finding that the change in the tariff is the key driver of export growth generalizes to the simpler models that abstract from new exporter dynamics. Here we find that models that generate exporter dynamics from a sunk cost only or exporter heterogeneity through a static decision from a fixed cost increases of the macro export intensity by much less, between 64 to 66 percent. To get these models to generate a similar increase in trade then requires additional changes in the technology of exporting to capture the aggregate growth.

Armed with a model that captures producer dynamics as well as the aggregate changes in trade, we next consider how measures of misallocation as in Restuccia and Rogerson (2009) and Hsieh and Klenow (2009) depend on firm involvement in trade in Colombia. Specifically, we show that empirically, measures of output misallocation and input misallocation are strongly related to export and import participation. We show that our model can generate a similar relationship related to exporting. In particular, we find that the unobserved resources invested in accessing foreign markets lead to some variation in to firm labor share. We also find that the tariff leads to a distortion in firm size. Some of this misallocation reflects true misallocation from firm's facing heterogeneous taxes on demand while another part reflects not properly accounting for fixed labor costs from production or export investments.

Our paper contributes to the recent literature that seeks to identify the effect of changes in trade barriers on trade and the distribution of activity within countries. Roberts and Tybout (1997) and Das, Roberts, and Tybout (2007) estimate a structural version of the Baldwin-Dixit-Krugman sunk cost of exporting model. Alessandria and Choi (2014) build a general equilibrium of the sunk cost model and use it to decompose the growth of US export growth. They show the sunk cost model can explain the dynamics of the aggregate trade flows and the heterogeneous responses of trade from a decline in tariffs and iceberg costs. In particular, the model is consistent with the stronger long-run response of trade than the 
short-run response. They emphasize that GE models that abstract from these producer-level dynamics would infer substantial changes in the fixed costs of exporting. We find a similar result here, as these simpler models understate trade growth substantially. Our paper is also related to empirical work that seeks to sort out the dynamic impact of trade liberalization methods. A series of papers (Baier and Bergstrand, 2007, Buono and Lalanne, 2012, and Baier, Bergstrand and Feng, 2014) find trade agreements have gradually effects on trade flows. Baier, Bergstrand, and Feng find that the trade growth from year 10 to 15 are almost as large as the growth in the first five years of a trade agreement and that much of the subsequent growth is related to changes in export participation.

A more recent literature pioneered by Ruhl and Willis (2008), Eaton et al (2008), Eaton et al (2009) argues that the benchmark dynamic model of exporting with a sunk cost is inconsistent with observed dynamics of new exporters. Kohn, Leibovici and Szkup (2015) develop a partial equilibrium trade model consistent with these new exporter dynamics based on financial frictions. Alessandria, Choi, and Ruhl (2015) develop a general equilibrium model consistent with new exporter dynamics with a more flexible exporting technology and use it to evaluate the aggregate implications of a policy change.

In Section 2, we review some evidence on heterogeneity in exporting. In Section 3, we lay out a model consistent with these features, and in Section 4, we describe our strategy for calibrating the model. Section 5 describes some results using the model.

\section{Data}

We summarize some aspects of the Colombian economy related to the changes in

trade, the micro-dynamics of trade, and the relationship between trade and measures of misallocation and international trade. 


\section{A. Aggregate Dynamics}

We begin by describing some of the changes in Colombian manufacturing exports from 1981 to 2013. This is a period in which exports grew quite fast relative to overall shipments so that Colombia become more globally integrated. We consider data on exports from both the Census of Manufactures and Customs. ${ }^{2}$ The producer-level data allows us to examine how the characteristics of exporters and non-exporters changed. Figure 5summarizes the key changes in manufacturing exports over this period.

To account for the role of changes in producer heterogeneity in aggregate export growth, suppose that only $n$ of the $N$ manufacturing establishments export. Let establishment $i$ have total sales sales $s_{i}=d_{i}+e x_{i}$ with $d_{i}$ and $e x_{i}$ being the domestic and export sales then the ratio of exports to total sales can be decomposed as,

$$
\frac{\text { Exports }}{\text { Total sales }}=\frac{\sum_{i=1}^{n} e x_{i}}{\sum_{i=1}^{N} \text { sales }_{i}}=\left(\frac{\sum_{i=1}^{n} e_{i} / n}{\sum_{i=1}^{n} \text { sales }_{i} / n}\right)\left(\frac{\sum_{i=1}^{n} \text { sales }_{i} / n}{\sum_{i=1}^{N} \text { sales }_{i} / N}\right)\left(\frac{n}{N}\right) \text {. }
$$

Over time, taking logs, the change in the ratio of exports to total sales can be decomposed into three components,

$$
\overbrace{\Delta E X S}^{\text {Export }} \overbrace{\Delta\left(\overline{\text { ex }}_{t} / \overline{\text { sales }}_{t}^{X}\right)}^{\text {Exporter }}+\overbrace{\Delta\left(\overline{\text { sales }}_{t}^{X} / \overline{\text { sales }_{t}}\right)}^{\text {Exporter }}+\overbrace{\Delta\left(n_{t} / N_{t}\right)}^{\text {premium }}+\overbrace{\text { participation }}^{\text {Export }}
$$

All of these components can be measured using the micro data. At the aggregate level, Colombian manufacturing exports as a share of manufacturing sales grew about 95 log points in 25 years from 1981/2 to 2006/7 (Table 1). Since the Great Recession, export integration has reversed a bit so that the net growth is about 83 log points.

\footnotetext{
${ }^{2}$ For the period 1981 to 1989 we use the Colombian Census. For the period from 1997 to 2013 we use the Colombian census merged with the customs data.
} 
For the average exporter (weighted by sales), exporter intensity grew only 46.3 log points. The much larger increase in the aggregate export share is accounted for by a large increase in export participation and a substantial decrease in the exporter premium. ${ }^{3}$ We also see that changes in export participation tend to be much more gradual than changes in the micro or macro export intensity.

Figure scatters the changes in the aggregate export intensity (relative to 1981) against the change in the micro export intensity. We see that the aggregate export intensity increases 1.85 times the producer export intensity.

In terms of identifying the change in iceberg costs, in all symmetric models with a constant elasticity of demand and an iceberg trade cost $^{4}$ the change in export intensity is driven only by changes in tariffs $(\tau)$ and iceberg costs $(\xi)^{5}$

$$
\Delta e x_{i}-\Delta d_{i}=-\theta \Delta \tau+(1-\theta) \Delta \xi_{i}
$$

Most existing theories treat iceberg costs as exogenous and unresponsive to changes in tariffs. In the theory we develop we allow producers to accumulate a better shipping technology $\xi_{i}$ in response to a change in trade barriers. ${ }^{6}$ We then can decompose the changes in export intensity due to exogenous and endogenous forces.

\section{B. Exporter Dynamics}

We now describe some salient features of exporter churning and the exporter life-cycle using the 1981 to 1989 panel (qualitatively similar results hold in the 97 to 13 panel). These moments have been emphasized in previous work on new exporter dynamics. These statistic

\footnotetext{
${ }^{3}$ The precise division between the participation and exporter premium margin can be sensitive to changes in the sample while the firm-level export intensity and aggregate export intensity are not sensitivity.

${ }^{4}$ This relationship holds even in a model with vertical specialization.

${ }^{5}$ Changes in relative demand across countries from changes in the real exchange rate or relative expenditures will also determine export intensity. In a symmetric world these naturally cancel out.

${ }^{6}$ Our theory also allows for the iceberg cost to respond endogenously to a change in iceberg costs.
} 
are summarized in table 2. First, there are many new exporters. Annually, about 18 percent of exporters are new to the market. Second, many of these starters have exported recently, with a recent exporter being 30 percent more likely to export. Third, while exporting is extremely persistent with over 90 percent of exporters continuing, many of these starters exit soon after entering. Indeed the typical starter has a 25 percent lower chance of continuing than a continuing exporter. In terms of size, new exporters don't amount to much exports. Even though annually new exporters are 17.6 percent of exporters, they only account for about 4.2 percent of exports. The relatively minor role of new exporters is attributed to them being small, with sales that are on average 40 percent of continuing exporters, and exporting less-intensively than continuing exporters, with initial export intensity of only 46 percent of continuing exporters. We also know that these new exporters eventually export as intensively as incumbents, but it takes time as the persistence of export intensity is about 94 percent. This suggests that it takes about 11 years for a new exporter to export as intensively as a continuing exporter.

\section{Misallocation}

We next consider how measures of misallocation are related to international trade. In particular, we follow Hsieh and Klenow to calculate some distortions using the Colombian census data and then show that these measures are related to a firm's involvement in trade.

To set ideas, consider the static profit maximization problem of a firm facing taxes on output, capital, and material inputs.

$$
\pi_{s i}=\left(1+\tau_{Y s i}\right) P_{s i} Y_{s i}-w L_{s i}-\left(1+\tau_{K s i}\right) r K_{s i}-\left(1+\tau_{M s i}\right) P_{M} M_{s i}
$$

subject to : $\quad Y_{s i}=B_{i t} P_{i t}^{-\sigma}$ 
From the profit maximization we can write out the marginal products of each input

$$
\begin{aligned}
M R P L & =\left(1-\alpha_{L s}\right) \frac{\sigma-1}{\sigma} \frac{P_{s i} Y_{s i}}{L_{s i}}=\frac{w}{1+\tau_{Y s i}} \\
M R P K & =\left(1-\alpha_{K s}\right) \frac{\sigma-1}{\sigma} \frac{P_{s i} Y_{s i}}{K_{s i}}=r \frac{1+\tau_{K s i}}{1+\tau_{Y s i}} \\
M R P M & =\left(1-\alpha_{M s}\right) \frac{\sigma-1}{\sigma} \frac{P_{s i} Y_{s i}}{K_{s i}}=P_{M} \frac{1+\tau_{M s i}}{1+\tau_{Y s i}}
\end{aligned}
$$

We can back out the distortion from some ratios on input usage and measures of elasticities and shares. Taking logs we get that

$$
\begin{aligned}
\ln \left(1+\tau_{Y s i}\right) & =\ln \frac{1}{1-\alpha_{L s}} \frac{\sigma}{\sigma-1}+\ln \frac{w L_{s i}}{P_{s i} Y_{s i}} \\
\ln \left(1+\tau_{K s i}\right) & =\ln \frac{1-\alpha_{K s}}{1-\alpha_{L s}}+\ln \frac{w L_{s i}}{r K_{s i}} \\
\ln \left(1+\tau_{M s i}\right) & =\ln \frac{1-\alpha_{M s}}{1-\alpha_{L s}}+\ln \frac{w L_{s i}}{P_{M} M_{s i}}
\end{aligned}
$$

Treating the first terms as an industry and year fixed effect, we can ask how dispersion is related to trade using Colombian data from 81 to 89 . In terms of the output distortion, $\tau_{Y_{s i}}$ it is clear that the assumption of common elasticity of substitution will be violated if exporters face a different demand elasticity. It is also clear that a differential tax or subsidy on exports or output will be a source of dispersion in the output distortion. Likewise it is clear that the input distortion $\tau_{Y_{s i}}$ will arise from differences in importing as it implies that firm's have different material costs and face different taxes on inputs. Finally, we emphasize that $\mathrm{L}_{s i}$ should be a measure of labor used in production. To the extent that some labor is being used for export market access this will also generate a distortion.

We begin by examining how the output tax depends on producer size and trade. Table 3 reports the results of a regression of the output wedge on year and industry fixed effects and age controls plus controls for size (based on material's purchased) and controls of export and import participation as well as the intensity of importing and exporting. We find, that 
the tax is lower for larger firms but higher for exporters and importers. We find that the tax is decreasing in export and import intensity.

We begin by examining how the input tax depends on producer size and trade. Table 4 reports the results of a regression of the output wedge on year and industry fixed effects and age controls plus controls for size (based on sales) and controls of export and import participation as well as the intensity of importing and exporting. The input tax is decreasing in size, measured as sales, but increasing in exporting and importing.

\section{Model}

We study Colombia's trade integration through a variation of the general equilibrium new exporter model of Alessandria, Choi and Ruhl (2015, ACR hereafter). In this model, when a producer starts to export it does so with a less efficient shipping technology (i.e. a higher iceberg cost) than an incumbent exporter. It then takes sustained export participation over time and a bit of luck for a new exporter to acquire the more efficient shipping technology and export as intensively as the typical incumbent exporter. We focus on the technology for shipping changing, but it is equivalent to have the foreign market to build up a taste for the firm's product. The nature of the technology for exporting generates a gradual expansion in the characteristics of exporters following a trade liberalization.

There are two symmetric countries: home and foreign, $\{H, F\}$. Each country is populated by a unit mass of identical, infinitely-lived consumers that inelastically supply one unit of labor. In each country, competitive final goods producers purchase home and foreign differentiated intermediate inputs. The final good is not traded and is used for consumption, investment, ${ }^{7}$ and as an input into production. There exists a one-period nominal bond, denominated in units of the home final good, that pays one unit of the home final good in the

\footnotetext{
${ }^{7}$ Capital accumulation is included to more accurately quantify the gain from trade. In most models, capital accumulation tends to increase the steady-state gain from a cut in trade barriers, but makes the steady-state change overstate the welfare gain. Hence, our results are even more surprising.
} 
next period. Let $B_{t}$ denote the home consumer's holding of bonds purchased in period $t$, $B_{t}^{*}$ denote the foreign consumer's holding of this bond, and let $Q_{t}$ denote the nominal bond price. The home final good is the numeraire, so $P_{t}=1$ in every period. With symmetric economies and symmetric policies, the foreign price level is $P_{t}^{*}=1$ and bond holdings are $B_{t}=0$. With asymmetric policies, the real exchange rate is $q_{t}=P_{t}^{*}$, and $B_{t}$ will vary. For now, we focus on a symmetric equilibrium.

Intermediate goods producers in each country are characterized by their productivity, fixed export cost, and iceberg trade cost. Productivity is stochastic. Iceberg costs have an endogenous and stochastic element, while the fixed cost is exogenous. The shocks to productivity and iceberg costs generate movements of establishments into and out of exporting; unproductive establishments exit and new establishments enter.

All intermediate goods producers sell to their own country, but only some export. Exporting requires paying fixed and variable costs. All exporters face the same ad valorem tariff, $\tau$, but differ in their iceberg transportation cost, $\xi_{\iota} \geq 1$, and fixed export costs. The tariff is a policy variable, and the revenues collected from the tariff are rebated lump-sum to consumers. The transportation cost is a feature of technology. Fraction $\xi_{i}-1$ of an export shipment is destroyed in transit. Fixed export costs are paid in units of domestic labor.

We depart from the literature in allowing for three possible iceberg costs $\xi \in\left\{\xi_{L}, \xi_{H}, \infty\right\}$ with $\xi_{L} \leq \xi_{H}<\infty$ and two possible fixed export costs $f \in\left\{f_{L}, f_{H}\right\}, f_{L} \leq f_{H}$. Fixed export costs and the variable iceberg costs are related. Producers with an iceberg cost of $\xi=\infty$ are non-exporters. A non-exporter attempts to lower its next-period iceberg cost to $\xi_{H}$ by paying a cost $f_{H}$. Relative to ACR (2014), we allow the return to this investment to be stochastic as only $\eta$ of these investment reduce the iceberg cost. An exporter with iceberg $\operatorname{costs} \xi_{t}=\left\{\xi_{L}, \xi_{H}\right\}$ can incur a cost $f_{L}$ to draw its next-period iceberg cost. We assume that the transition probabilities are Markovian and that the probability of drawing the low iceberg $\operatorname{costs}, \xi_{L}$, is lower for an exporter with a high iceberg cost than a producer with a low 
iceberg cost (i.e., $\left.\rho_{\xi}\left(\xi_{L} \mid \xi_{H}\right) \leq \rho_{\xi}\left(\xi_{L} \mid \xi_{L}\right)\right)$. Thus, part of exporting is making an investment that may lead to a lower marginal cost of exporting in the future. If an exporter does not pay $f_{L}$, it is choosing to exit the export market, and its next period iceberg cost rises to $\xi=\infty$.

This formulation of fixed and iceberg costs is quite general and nests the most common approaches to modeling trade. First, when there is no uncertainty in export participation so that $\eta=1$ then if $f_{L}<f_{H}$, there is a sunk cost of exporting, as in Das, Roberts, and Tybout (2007). When $f_{L}=f_{H}$ and $\xi_{L}=\xi_{H}$, exporting is a static decision. When $f_{L}=f_{H}=0$ and $\xi_{L}=\xi_{H}$, there is no export decision, and this is a general version of the Krugman (1980) model of monopolistic competition. When $\eta<1$ the outcome of investing in exporting is uncertain and our model has an element of either the search model of Eaton et al (2009) or time to build.

To close the model an establishment is created by hiring $f_{E}$ domestic workers and begins producing in the following period. The measure of country $j \in\{H, F\}$ establishments with technology $z$, iceberg $\operatorname{costs} \xi$, and fixed costs $f$ is $\varphi_{j, t}(z, \xi, f)$. Establishment exit ("death") is exogenous and depends on the current productivity level. The state variable of the economy includes the measure of establishments across individual state variables from each country and the capital stock in each country. For notational ease, economy-wide state variables are subsumed in the time subscript.

\section{A. Consumers}

Home consumers choose consumption, investment, and bonds to maximize utility subject to the sequence of budget constraints,

$$
\begin{gathered}
V_{C, 0}=\max E_{0} \sum_{t=0}^{\infty} \beta^{t} U\left(C_{t}\right), \\
C_{t}+K_{t}+Q_{t} B_{t} \leq W_{t} L_{t}+R_{t} K_{t-1}+(1-\delta) K_{t-1}+B_{t-1}+\Pi_{t}+T_{t},
\end{gathered}
$$


where $\beta \in(0,1)$ is the subjective time discount factor; $C_{t}$ is final consumption; $K_{t-1}$ is the capital available in period $t ; W_{t}$ and $R_{t}$ denote the real wage rate and the rental rate of capital; $\delta$ is the depreciation rate of capital; $\Pi_{t}$ is real dividends from home producers; and $T_{t}$ is the real lump-sum transfer of local tariff revenue. Investment is $I_{t}=K_{t}-(1-\delta) K_{t-1}$.

The foreign consumer's problem is analogous. Foreign prices and allocations are denoted with an asterisk. The foreign budget constraint is

$$
P_{t}^{*} C_{t}^{*}+P_{t}^{*} K_{t}^{*}+Q_{t} P_{t}^{*} B_{t}^{*} \leq W_{t}^{*} P_{t}^{*} L_{t}^{*}+R_{t}^{*} P_{t}^{*} K_{t-1}^{*}+(1-\delta) P_{t}^{*} K_{t-1}^{*}+P_{t}^{*} B_{t-1}^{*}+\Pi_{t}^{*}+T_{t}^{*},
$$

where all prices are quoted in units of the home final good.

The first-order conditions for the consumers' utility maximization problems are

$$
\begin{aligned}
Q_{t} & =\beta E_{t} \frac{U_{C, t+1}}{U_{C, t}}=\beta E_{t} \frac{U_{C, t+1}^{*}}{U_{C, t}^{*}} \frac{P_{t}^{*}}{P_{t+1}^{*}}, \\
1 & =\beta E_{t} \frac{U_{C, t+1}}{U_{C, t}}\left(R_{t+1}+1-\delta\right)=\beta E_{t} \frac{U_{C, t+1}^{*}}{U_{C, t}^{*}} \frac{P_{t}^{*}}{P_{t+1}^{*}}\left(P_{t+1}^{*} R_{t+1}^{*}+1-\delta\right),
\end{aligned}
$$

where $U_{C, t}$ denotes the derivative of the utility function with respect to its argument. Equation 3 is the no-arbitrage condition for bonds that equates the difference in expected consumption growth across countries to the expected change in the real exchange rate. Equation 4 is the standard Euler equation for capital accumulation in each country.

\section{B. Final Goods Producers}

Final goods are produced by combining home and foreign intermediate goods. The aggregation technology is a CES function

$$
D_{t}=\left\{\sum_{j \in\{H, F\}} \sum_{\xi \in\left\{\xi_{L}, \xi_{H}, \infty\right\}} \int_{z} y_{j, t}^{d}(z, \xi, f)^{\frac{\theta-1}{\theta}} \varphi_{j, t}(z, \xi, f) d z\right\}^{\frac{\theta}{\theta-1}}
$$


where $y_{j, t}^{d}(z, \xi, f)$ are inputs of intermediate goods purchased from country $j$ intermediate good producers. The elasticity of substitution between intermediate goods is $\theta>1$.

The final goods market is competitive. Given the price of inputs, the final goods producer chooses purchases of intermediate inputs, $y_{j, t}^{d}$, to solve

$$
\begin{aligned}
\max \Pi_{F, t} & =D_{t}-\sum_{\xi \in\left\{\xi_{L}, \xi_{H}, \infty\right\}} \int_{z} P_{H, t}(z, \xi, f) y_{H, t}^{d}(z, \xi, f) \varphi_{H, t}(z, \xi, f) d z \\
& -(1+\tau) \sum_{\xi \in\left\{\xi_{L}, \xi_{H}\right\}} \int_{z} P_{F, t}(z, \xi, f) y_{F, t}^{d}(z, \xi, f) \varphi_{F, t}(z, \xi, f) d z
\end{aligned}
$$

subject to the production technology in (5). Here, $P_{j, t}(z, \xi, f)$ are the home-country prices of intermediate goods produced in country $j$ establishments. Solving the problem in (6) yields the input demand functions,

$$
\begin{aligned}
& y_{H, t}^{d}(z, \xi, f)=\left[P_{H, t}(z, \xi, f)\right]^{-\theta} D_{t} \\
& y_{F, t}^{d}(z, \xi, f)=\left[(1+\tau) P_{F, t}(z, \xi, f)\right]^{-\theta} D_{t}
\end{aligned}
$$

where the final goods price is defined as

$$
\begin{aligned}
& P_{t}^{1-\theta}= \\
& \quad \sum_{\xi \in\left\{\xi_{L}, \xi_{H}, \infty\right\}} \int_{z}\left[P_{H, t}(z, \xi, f)^{1-\theta} \varphi_{H, t}(z, \xi, f)+\left[(1+\tau) P_{F, t}(z, \xi, f)\right]^{1-\theta} \varphi_{F, t}(z, \xi, f)\right] d z .
\end{aligned}
$$

\section{Intermediate Goods Producers}

An intermediate goods producer is described by its technology, iceberg cost, and fixed cost, $(z, \xi, f)$. It produces using capital, $k$, labor, $l$, and materials, $x$, according to

$$
y_{t}(z, \xi, f)=e^{z}\left[k_{t}(z, \xi, f)^{\alpha} l_{t}(z, \xi, f)^{1-\alpha}\right]^{1-\alpha_{x}} x(z, \xi, f)^{\alpha_{x}}
$$


The markets that the producer serves in the current period are predetermined, so the producer maximizes current-period gross profits by choosing prices for each market, $P_{H, t}(z, \xi, f)$ and $P_{H, t}^{*}(z, \xi, f)$, labor $l_{t}(z, \xi, f)$, capital $k_{t}(z, \xi, f)$, and materials $x_{t}(z, \xi, f)$ to solve

$$
\begin{aligned}
\Pi_{t}(z, \xi, f) & =\max P_{H, t}(z, \xi, f) y_{H, t}(z, \xi, f)+P_{H, t}^{*}(z, \xi, f) y_{H, t}^{*}(z, \xi, f) \\
& -W_{t} l_{t}(z, \xi, f)-R_{t} k_{t}(z, \xi, f)-P_{t} x_{t}(z, \xi, f)
\end{aligned}
$$

subject to the production technology (10), a constraint that supplies to home and foreign goods markets, $y_{H, t}(z, \xi, f)$ and $y_{H, t}^{*}(z, \xi, f)$, are feasible

$$
y_{t}(z, \xi, f)=y_{H, t}(z, \xi, f)+\xi y_{H, t}^{*}(z, \xi, f)
$$

and the constraints that supplies to home and foreign goods markets are equal to the demands from final good producers from (7) and its foreign analogue,

$$
\begin{aligned}
& y_{H, t}(z, \xi, f)=y_{H, t}^{d}(z, \xi, f), \\
& y_{H, t}^{*}(z, \xi, f)=y_{H, t}^{d *}(z, \xi, f) .
\end{aligned}
$$

Given its downward-sloping demand curve, the monopolistic producer charges a constant markup over marginal cost in each market,

$$
\begin{aligned}
& P_{H, t}(z, \xi, f)=\frac{\theta}{\theta-1} M C_{t} e^{-z} \\
& P_{H, t}^{*}(z, \xi, f)=\frac{\theta}{\theta-1} \xi M C_{t} e^{-z}
\end{aligned}
$$


where

(17) $M C_{t}=\alpha_{x}^{-\alpha_{x}}\left(1-\alpha_{x}\right)^{-\left(1-\alpha_{x}\right)}\left[\left(\frac{R_{t}}{\alpha}\right)^{\alpha}\left(\frac{W_{t}}{1-\alpha}\right)^{1-\alpha}\right]^{1-\alpha_{x}}$.

Note that when $\xi=\infty$, the producer is a non-exporter.

The value of the producer with $(z, \xi, f)$, if it decides to try to export in period $t+1$, is

$V_{t}^{1}(z, \xi, f)=-W_{t} f+n_{s}(z) Q_{t}\left(\int_{z^{\prime}} \eta \sum_{\xi^{\prime} \in\left\{\xi_{L}, \xi_{H}\right\}} V_{t+1}\left(z^{\prime}, \xi^{\prime}, f_{L}\right) \rho_{\xi}\left(\xi^{\prime} \mid \xi\right)+(1-\eta) V_{t+1}\left(z^{\prime}, \infty, f_{H}\right) \phi\left(z^{\prime} \mid z\right) d z^{\prime}\right)$

and the value of the producer, if it does not export in period $t+1$, is

$$
V_{t}^{0}(z, \xi, f)=n_{s}(z) Q_{t} \int_{z^{\prime}} V_{t+1}\left(z^{\prime}, \infty, f_{H}\right) \phi\left(z^{\prime} \mid z\right) d z^{\prime}
$$

where $n_{s}(z)$ is the probability that the producer survives until the next period. Note that this probability varies with the producer's productivity. The value of the producer is

$$
V_{t}(z, \xi, f)=\Pi_{t}(z, \xi, f)+\max \left\{V_{t}^{1}(z, \xi, f), V_{t}^{0}(z, \xi, f)\right\}
$$

Clearly, the value of a producer depends on its fixed cost, iceberg cost, and productivity. Given that there are three possible levels of iceberg costs, there are now three possible cutoffs, $z_{m, t}$, with $m \in\{L, H, \infty\}$. The critical level of productivity for exporting, $z_{m, t}$, satisfies

$$
V_{t}^{1}\left(z_{m, t}, \xi_{m}, f\right)=V_{t}^{0}\left(z_{m, t}, \xi_{m}, f\right)
$$

It is straightforward to show that the threshold for exporting is largest for non- 
exporters and smallest for exporters with the low iceberg $\operatorname{cost}\left(z_{\infty, t}>z_{H, t} \geq z_{L, t}\right)$.

\section{Entry}

New establishments are created by hiring $f_{E}$ workers in the period prior to production. Entrants draw their productivity from the distribution $\phi_{E}\left(z^{\prime}\right)$. Entrants cannot export in their first productive period. The free-entry condition is

$$
V_{t}^{E}=-W_{t} f_{E}+Q_{t} \int_{z^{\prime}} V_{t+1}\left(z^{\prime}, \infty, f_{H}\right) \phi_{E}\left(z^{\prime}\right) d z^{\prime} \leq 0
$$

The mass of entrants in period $t$ is $N_{E, t}$, while the mass of incumbents, $N_{t}$, consists of the two types of exporters and the non-exporters,

$$
\begin{aligned}
& N_{L, t}=\int_{z} \varphi_{H, t}\left(z, \xi_{L}, f_{L}\right) d z \\
& N_{H, t}=\int_{z} \varphi_{H, t}\left(z, \xi_{H}, f_{L}\right) d z, \\
& N_{\infty, t}=\int_{z} \varphi_{H, t}\left(z, \infty, f_{H}\right) d z
\end{aligned}
$$

The mass of exporters equals $N_{1, t}=N_{L, t}+N_{H, t}$; the mass of non-exporters equals $N_{0, t}=N_{\infty, t}$; and the mass of establishments equals $N_{t}=N_{1, t}+N_{0, t}$. The fixed costs of exporting imply that only a fraction, $n_{x, t}=N_{1, t} / N_{t}$, of home intermediates are available in the foreign country in period $t$.

Given the critical level of productivity for exporters and non-exporters, $z_{m, t}$, the starter ratio (the fraction of establishments among non-exporters that start exporting) and the stopper ratio (the fraction of exporters among surviving establishments who stop exporting) are, 
respectively,

(26) $n_{0, t+1}=\frac{\int_{z_{\infty, t}}^{\infty} \eta n_{s}(z) \varphi_{H, t}\left(z, \infty, f_{H}\right) d z}{\int_{z} n_{s}(z) \varphi_{H, t}\left(z, \infty, f_{H}\right) d z}$,

$$
n_{1, t+1}=\frac{\sum_{m \in\{L, H\}} \int_{-\infty}^{z_{m, t}} n_{s}(z) \varphi_{H, t}\left(z, \xi_{m}, f_{L}\right) d z}{\sum_{m \in\{L, H\}} \int_{z} n_{s}(z) \varphi_{H, t}\left(z, \xi_{m}, f_{L}\right) d z}
$$

The mass of establishments evolves according to

$$
\begin{aligned}
\varphi_{t+1}\left(z^{\prime}, \infty, f_{H}\right) & =\sum_{m \in\{L, H, \infty\}} \int_{-\infty}^{z_{m, t}} n_{s}(z) \varphi_{H, t}\left(z, \xi_{m}, f\right) \phi\left(z^{\prime} \mid z\right) d z+N_{E, t} \phi_{E}\left(z^{\prime}\right) \\
& +\int_{z_{\infty, t}}^{\infty}(1-\eta) n_{s}(z) \varphi_{H, t}\left(z, \xi_{\infty}, f\right) \phi\left(z^{\prime} \mid z\right) d z \\
\varphi_{t+1}\left(z^{\prime}, \xi_{H}, f_{L}\right) & =\sum_{m \in\{L, H\}} \rho_{\xi}\left(\xi_{H} \mid \xi_{m}\right) \int_{z_{m, t}}^{\infty} n_{s}(z) \varphi_{H, t}\left(z, \xi_{m}, f\right) \phi\left(z^{\prime} \mid z\right) d z \\
& +\rho_{\xi}\left(\xi_{H} \mid \xi_{\infty}\right) \eta \int_{z_{\infty, t}}^{\infty} n_{s}(z) \varphi_{H, t}\left(z, \xi_{\infty}, f\right) \phi\left(z^{\prime} \mid z\right) d z \\
\varphi_{t+1}\left(z^{\prime}, \xi_{L}, f_{L}\right) & =\sum_{m \in\{L, H\}} \rho_{\xi}\left(\xi_{L} \mid \xi_{m}\right) \int_{z_{m, t}}^{\infty} n_{s}(z) \varphi_{H, t}\left(z, \xi_{m}, f\right) \phi\left(z^{\prime} \mid z\right) d z \\
& +\rho_{\xi}\left(\xi_{L} \mid \xi_{\infty}\right) \eta \int_{z_{\infty}, t}^{\infty} n_{s}(z) \varphi_{H, t}\left(z, \xi_{\infty}, f\right) \phi\left(z^{\prime} \mid z\right) d z .
\end{aligned}
$$

\section{E. Government and Aggregate Variables}

The government collects tariffs and redistributes the revenue lump-sum to domestic consumers. The government's budget constraint is

$$
T_{t}=\tau \sum_{\xi \in\left\{\xi_{L}, \xi_{H}\right\}} \int_{z} P_{F, t}\left(z, \xi, f_{L}\right) y_{F, t}\left(z, \xi, f_{L}\right) \varphi_{F, t}\left(z, \xi, f_{L}\right) d z
$$


Nominal exports and imports are, respectively,

$$
\begin{aligned}
& E X_{t}^{N}=\sum_{\xi \in\left\{\xi_{L}, \xi_{H}\right\}} \int_{z} P_{H, t}^{*}\left(z, \xi, f_{L}\right) y_{H, t}^{*}\left(z, \xi, f_{L}\right) \varphi_{H, t}\left(z, \xi, f_{L}\right) d z \\
& I M_{t}^{N}=\sum_{\xi \in\left\{\xi_{L}, \xi_{H}\right\}} \int_{z} P_{F, t}\left(z, \xi, f_{L}\right) y_{F, t}\left(z, \xi, f_{L}\right) \varphi_{F, t}\left(z, \xi, f_{L}\right) d z
\end{aligned}
$$

Home nominal GDP is the sum of value added from intermediate and final goods producers, $Y_{t}^{N}=C_{t}+I_{t}+E X_{t}^{N}-I M_{t}^{N}$. The trade-to-GDP ratio is $T R_{t}=\frac{E X_{t}^{N}+I M_{t}^{N}}{2 Y_{t}^{N}}$, and $I M D_{t}$ is the expenditure on imported goods relative to home goods,

$$
I M D_{t}=\frac{\left(1+\tau_{t}\right) \sum_{\xi \in\left\{\xi_{L}, \xi_{H}\right\}} \int_{z} P_{F, t}\left(z, \xi, f_{L}\right) y_{F, t}\left(z, \xi, f_{L}\right) \varphi_{F, t}\left(z, \xi, f_{L}\right) d z}{\sum_{\xi \in\left\{\xi_{L}, \xi_{H}, \infty\right\}} \int_{z} P_{H, t}(z, \xi, f) y_{H, t}(z, \xi, f) \varphi_{H, t}(z, \xi, f) d z}
$$

so the share of expenditures on domestic goods is

(38) $\lambda_{t}=\frac{1}{1+I M D_{t}}$,

and the trade elasticity is

$$
\varepsilon_{t}=-\frac{\ln \left(I M D_{t} / I M D_{-1}\right)}{\ln \left(\left(1+\tau_{t}\right) /\left(1+\tau_{-1}\right)\right)}
$$

Notice that the trade elasticity is based on expenditures including taxes.

Labor used in production, rather than to pay fixed costs, $L_{P, t}$, is

$$
L_{P, t}=\sum_{\xi \in\left\{\xi_{L}, \xi_{H}, \infty\right\}} \int_{z} l_{t}(z, \xi, f) \varphi_{H, t}(z, \xi, f) d z
$$


The domestic labor hired by exporters to cover the fixed costs of exporting, $L_{X, t}$, equals

$$
L_{X, t}=\sum_{m \in\{L, H\}} f_{L} \int_{z_{m, t}}^{\infty} \varphi_{H, t}\left(z, \xi_{m}, f_{L}\right) d z+f_{H} \int_{z_{\infty, t}}^{\infty} \varphi_{H, t}\left(z, \infty, f_{H}\right) d z
$$

From (41), we see that the trade cost, measured in units of domestic labor, depends on the exporter status from the previous period. Aggregate profits are the difference between profits and fixed costs,

$$
\Pi_{t}=\sum_{\xi \in\left\{\xi_{L}, \xi_{H}, \infty\right\}} \int_{z} \Pi_{t}(z, \xi, f) \varphi_{H, t}(z, \xi, f) d z-W_{t} L_{X, t}-W_{t} f_{E} N_{E, t}
$$

Even though there is free entry in the model, aggregate profits are generally positive. These profits compensate firm owners for waiting for their investment in producers to mature.

\section{F. Equilibrium Definition}

In an equilibrium, variables satisfy several resource constraints. The final goods market-clearing conditions are $D_{t}=C_{t}+I_{t}+X_{t}$, and $D_{t}^{*}=C_{t}^{*}+I_{t}^{*}+X_{t}^{*}$, where $X_{t}$ is total material inputs in production, given by

$$
X_{t}=\sum_{\xi \in\left\{\xi_{L}, \xi_{H}, \infty\right\}} \int_{z} x_{t}(z, \xi, f) \varphi_{H, t}(z, \xi, f) d z
$$

Each individual goods market clears; the labor market-clearing conditions are $L=L_{P, t}+$ $L_{X, t}+f_{E} N_{E, t}$ and the foreign analogue; the capital market-clearing conditions are

$$
K_{t-1}=\sum_{\xi \in\left\{\xi_{L}, \xi_{H}, \infty\right\}} \int_{z} k_{t}(z, \xi, f) \varphi_{H, t}(z, \xi, f) d z
$$

and the foreign analogue. The government budget constraint is given by (34) and the foreign analogue. The profits of each country's establishments, $\Pi_{t}$, are distributed to its consumers. 
The international bond market-clearing condition is given by $B_{t}+B_{t}^{*}=0$.

An equilibrium of the economy is a collection of allocations for home consumers $C_{t}$, $B_{t}$, and $K_{t}$; allocations for foreign consumers $C_{t}^{*}, B_{t}^{*}$, and $K_{t}^{*}$; allocations for home final goods producers; allocations for foreign final goods producers; allocations, prices, and export decisions for home intermediate producers; allocations, prices, and export decisions for foreign intermediate producers; labor used for exporting costs and for entry costs by home and foreign producers; transfers $T_{t}, T_{t}^{*}$ by home and foreign governments; real wages $W_{t}, W_{t}^{*}$, real rental rates of capital $R_{t}, R_{t}^{*}$, and bond prices $Q_{t}$ that satisfy the following conditions: (i) the consumer allocations solve the consumer's problem; (ii) the final good producers' allocations solve their profit-maximization problems; (iii) intermediated good producers' allocations, prices, and export decisions solve their profit-maximization problems; (iv) the entry conditions holds; (v) the market-clearing conditions hold; and (vi) the transfers satisfy the government budget constraint.

\section{Calibration}

We calibrate the model to match features of the Colombian economy in 1981/82. We first describe the functional forms and parameter values of our benchmark economy. The parameter values are summarized in Table 5 .

The instantaneous utility function is $U(C)=\frac{C^{1-\sigma}}{1-\sigma}$, where $1 / \sigma$ is the intertemporal elasticity of substitution. The discount factor, $\beta$, depreciation rate, $\delta$, and risk aversion, $\sigma$, are standard: $\beta=0.96, \delta=0.10$, and $\sigma=1$.

The distribution of establishments is determined by the structure of shocks. To eliminate the role of the elasticity of substitution, $\theta$, in establishment dispersion, we assume that producer productivity $z=\frac{1}{\theta-1} \ln a$. An incumbent's productivity has an autoregressive component $(\rho<1)$ of $\ln a^{\prime}=\rho \ln a+\varepsilon, \varepsilon \stackrel{i i d}{\sim} N\left(0, \sigma_{\varepsilon}^{2}\right)$. With an $\operatorname{AR}(1)$ shock process, the conditional distribution is normal, $\phi\left(\ln a^{\prime} \mid \ln a\right)=N\left(\rho \ln a, \sigma_{\varepsilon}^{2}\right)$, and the unconditional dis- 
tribution is $N\left(0, \frac{\sigma_{\varepsilon}^{2}}{1-\rho^{2}}\right)$. Entrants draw productivity based on the unconditional distribution $\ln a^{\prime}=\mu_{E}+\varepsilon_{E}, \varepsilon_{E} \stackrel{i i d}{\sim} N\left(0, \frac{\sigma_{\varepsilon}^{2}}{1-\rho^{2}}\right)$, where $\mu_{E}<0$ is chosen to match the observation that entrants are smaller than incumbents. Establishments receive an exogenous death shock that depends on an establishment's previous-period productivity, $a$; the probability of death is $n_{d}(a)=1-n_{s}(a)=\max \left\{0, \min \left\{e^{-\lambda a}+n_{d 0}, 1\right\}\right\}$.

The parameter $\theta$ determines both the producer's markup and the elasticity of substitution across varieties. We set $\theta=5$ to yield a producer markup of 25 percent. There is much heterogeneity in tariffs across sectors and in export subsidies. We assume this producer level heterogeneity is accounted for by our heterogenous trade costs and thus set the initial tariff rate to ten percent.

Recall that four parameters determine the dynamics of export intensity: the two iceberg costs $\left\{\xi_{H}, \xi_{L}\right\}$ and the transition probabilities, which we denote $\left\{\rho_{L L}, \rho_{H H}\right\}$. For simplicity, we assume that $\rho_{L L}=\rho_{H H}=\rho_{\xi}$, so that three parameters determine producerlevel export intensity dynamics.

The labor share parameter in production, $\alpha$, is set to match the ratio of labor income to GDP in the United States (66 percent). In the model, $\alpha_{x}$ determines the ratio of value added to gross output in manufacturing. In the United States, this ratio averaged 2.8 from 1987 to 1992 and implies that $\alpha_{x}=0.81$. The entry cost, $f_{E}$, is set to normalize the total mass of establishments, $N$, to one. The mean establishment size is normalized to the mean establishment size in the Colombia in 1981 and 1982.

The eleven parameters, $\left\{\lambda, n_{d}, \rho_{z}, \sigma_{z}^{2}, \mu_{E}, f_{L}, f_{H}, \xi_{L}, \xi_{H}, \rho_{\xi}, \eta\right\}$, are chosen to match the following observations:

1. An initial aggregate export-to-sales ratio of 5.5 percent

2. The exporter size distribution.

3. A weighted mean export intensity of 13.3 percent.

4. An initial export intensity of half the mean export intensity.

5. A five-year export intensity twice the initial export intensity .

6. A stopper rate of 18.0 percent. 
7. Establishment employment size distribution.

8. Five-year exit rate for entrants of 37 percent .

9. Entrants' labor share of 1.5 percent

10. Shut-down establishments' labor share of 2.3 percent.

The first six targets largely summarize the dynamics of export intensity and determine the technology for shipping $\left(\xi_{L}, \xi_{H}, \rho_{\xi}, f_{L}, f_{H}, \eta\right)$. The next four targets help pin down the establishment creation, destruction, and growth process $\left(\rho_{z}, \sigma_{\varepsilon}, \lambda, \mu_{E}, n_{d}\right)$. Newborn establishments and dying establishments tend to have few employees, and newborn establishments have high failure rates. The final three targets are based on the US but can be updated based on the work of Roberts (96).

The model is calibrated to match some aggregate measures of trade and some aspects of producer heterogeneity. ${ }^{8}$ Figure 3 depicts the characteristics of Colombian producers at the start of the sample (averaged over 1982 and 1983) that we target. We focus on producers with at least 10+ employees (measured in efficiency units of labor). The top panel shows the producer size distribution on a log scale (expressed as a share of plants with 10+ employees). Most plants have relatively few employees, although the most common plant has between 20 and 100 employees. There are relatively few plants with 500 or more employees. The middle panel shows how employees are distributed over these heterogeneous producers. Most workers are working at plants with 1000+ employees, with nearly 35 percent of employment at plants with $1000+$ employees. The bottom panel shows that rate of export participation is increasing in plant size, although there are many plants with $1000+$ employees who do not export.

Our model captures these features of the size distribution of producers and export participation quite well. There are not quite enough plants with 500+ employees and the plants with $1000+$ employees are a bit too big. In terms of export participation, the theory generates export participation that rises with size, although the the increase in size is too steep for mid-sized plants and not increasing enough for the largest plants.

\footnotetext{
${ }^{8}$ To calibrate the model we need to make a couple of adjustments to the data. First, we rank firms by their efficiency units of labor. Second, since small producers are under-represented in the Census data we make an adjustment by assuming that the small producers in our sample are representative of all small producers but sampled only 12.5 percent. This assumption has a minor effect on output or trade since these producers are small and unlikely to export.
} 
The top panel shows that the model generates relatively few relative large firms. The middle panel reports the employment share in each size bin in the data and model. Here the fit is almost perfect for the share of producers between 10 and 500 employees. There is not enough employment in producers with 500 to 1000 employees and too much employment in 1000+ producers, even though the model has too few large producers. The bottom panel depicts export participation by size. Here the model captures the increase in participation by size, although it flattens out more in the model than the data when going between the largest two categories.

Table 5 reports the key parameters and some moments from the model. The model captures the aggregate export share but understates the producer level export intensity (13.2 vs 12.3 percent). It generates substantially churning in the export market with 18.5 percent of exporters exiting. These new exporters account for relatively little of overall exports.

\section{A. Results}

We begin by exploring the impact on the economy of eliminating the 10 percent tariff for Colombia and the ROW. We focus on the change in the stationary steady state. ${ }^{9}$ Table 6 reports the change in the macro and micro export intensity in the model and the data. The model closely matches the change in the macro and micro export intensity. The micro export intensity grows 45.2 percent through 2007 compared to 47.0 percent in the model. The macro export intensity grows 95.5 percent in the data while it only grows 74.3 percent in the model. Overall, we find the ratio of the macro to micro elasticity is 1.58 compared to 2.11 in the data.

In addition to an extensive margin of trade, our model features an endogenous intensive margin. It is straightforward to decompose the change in the micro export intensity margin into an exogenous and endogenous component. Recall that the change in micro export intensity is

$$
\Delta e x_{i}-\Delta d_{i}=-\theta \Delta \tau+(1-\theta) \Delta \xi_{i} .
$$

\footnotetext{
${ }^{9}$ We also intend to consider asymetric reforms.
} 
Rearranging things and using our assumption of $\theta=5$, we can calculate the elasticity of trade costs to tariffs

$$
\varepsilon_{\tau}^{\xi}=\frac{\Delta \xi_{i}}{\Delta \tau}=\frac{\frac{\Delta e x_{i}-\Delta d_{i}}{\Delta \tau}+\theta}{1-\theta}=\frac{0.85}{4} \approx 0.21
$$

We thus infer that the average exporter improved its shipping technology by 2.1 percent.

Now while the model closely captures the change in the micro export intensity, it understates the macro export intensity by nearly 20 log points. As evidence of this failure, Figure 6 shows that the model understates export participation across all size categories ${ }^{10}$ and that the amount of the miss is increasing in size. We thus need a policy or technology change that operates primarily by inducing more exporting but not in a way that affects the micro export intensity. The most straightforward possibility is for the technology for investments in the technology for exporting to be more successful. We consider an increase in the technology from $\eta=0.147$ to $\eta=0.25$ so that a producer that invests in exporting is much more likely to export.

By changing the outcome of an investment in market access, we find that the model matches the macro export intensity of 95.5 with only a small increase in the micro export intensity to 47.8 percent. Additionally, the model closely captures the distribution of export participation by size along with the churning we see in the data.

We also consider changing the up-front entry cost and continuation cost individually and jointly to achieve the same increase in the macro export intensity (Table 6). Each of these technology changes leads to a larger role of the micro export intensity to 49 to 54 percent. They also lead to substantial changes in the persistence of exporting, suggesting these are less likely to matte much.

\section{B. Alternative model}

We next explore how well models that abstract from new exporter dynamics can account for the growth in Colombian exports. In particular, we consider a variation of the

\footnotetext{
${ }^{10}$ The smallest size categories in the model and the data are not directly comparable as the survey does not accurately capture the presence of small produces while there are no sampling problems in the model. Unlike the 1981/82 sample we do not adjust for this sample in the data here, although it is straightforward to.
} 
sunk cost model of exporting developed by Das, Roberts, and Tybout (2007) and extended to general equilibrium in Alessandria and Choi (2014) as well as a variation in which there is no sunk cost. In each of these model we parameterize the models to get the same initial exporter export intensity and overall trade share. Essentially, we set $\eta=1, \xi_{H}=\xi_{L}$ and then vary the iceberg cost and fixed costs to capture the micro and macro export intensity. Additionally, in the sunk cost model we vary the dispersion in idiosyncratic shocks, $\sigma$ to get a similar stopper rate as in our benchmark model. These are preliminary calibrations.

The third and fourth columns of Table 5 report parameters of the estimated model. These models miss out substantially on the distribution of export participation and overstate the importance of new exporting, particularly the fixed cost model which also has almost 40 percent of exporters being new exporters. The last two rows of 6 report the changes in the micro and macro export intensity in these alternative models from a 10 percent cut in tariff. Both models generate the same change in the micro export elasticity.

These two alternative models generate a smaller expansion in the micro export intensity of 40.4 percent compared to 47.0 percent in our benchmark model. They also generate movements in overall trade that are only 1.59 to 1.64 times the movement in the extensive margin. In total, we find that the new exporter model generates a stronger expansion through the extensive and intensive margins. To generate the same expansion in trade in these alternative model will require introducing a broader range of policy interventions.

\section{Aggregate Implications}

Our general equilibrium model is well-suited to evaluate the aggregate implications of this change in tariff policy. ${ }^{11}$ The top panel of Figure plots the dynamics of consumption, plant creation, and the bottom panel plots the micro and macro export intensity plus the change in export participation in a variation of our model with no capital and no intermediates. In general, including these magnify the gains along the transition but have a minor impact on the long-run consumption change or the dynamics of trade.. We compute the transition assuming an unanticipated decline in tariffs and improvement in the return to investment in

\footnotetext{
${ }^{11}$ The transition here is for a variation with no capital and no intermediates. In general, including these magnify the gains along the transition but have a minor impact on the the long-run consumption change or the dynamics of trade.
} 
exporting.

A global reduction in tariffs and improvement in the return to investing in market access leads to a boom in consumption that maxes out about 1.2 percent above the original level and then reverts back so that the long-run consumption gain is 0.54 percent. This overshooting is a familiar feature of dynamic models of exporting (see Alessandria and Choi, 2014, and Alessandria, Choi and Ruhl, 2014). The overshooting occurs even though trade grows gradually and reflects the dynamics of plant creation, which initially frees up resources for production but in the long-run reduces the scale of the economy. In terms of trade dynamics, we see that the micro export intensity expands non-monotonically while the macro export intensity and export participation rise monotonically. The non-monotonic nature of the micro export intensity arises from the surge in export entry brings in a lot of relatively inefficient exporters that lower the micro export intensity after the first period surge from the decline in tariffs (recall we assume there is a large between paying the export cost and exporting). As some of these young inefficient exporters mature, we see that the shipping technology gradually improves. We find that the model generates a gradual expansion of exports with the short-run trade response less than half of the long-run response.

\section{Misallocation and Trade}

Here we examine the ability of the model to generate misallocation similar to the data. [To be completed]

\section{Conclusion}

This paper studies empirically and theoretically Colombia's trade integration over an almost 30 year period. We calibrate a variation of the dynamic heterogenous producer model

of Alessandria, Choi and Ruhl to Colombia in the early 1980s and then examine the ability of the model to capture the changes in the producer level participation in export markets from a common change in tariffs and an improvement in the efficiency of investments in market access. Perhaps surprisingly, given the diverse range of policy changes undertaken, we find that the model closely matches the observed changes in the extensive and intensive margin of trade in this period from these two changes. Perhaps other policies or technological changes can also generate the same observed changes, although in our preliminary work we find that 
changes in fixed export costs ultimately generate too much growth through the intensive margin and substantially affect the churning in export markets in counterfactual ways.

We use the model to split the growth in exports into a part due to the policy change and the endogenous response of trade participation and the shipping technology to the change in trade policy. We find that endogenous response of exporters magnified the change in tariffs by about 80 percent. Models without new exporter dynamics generate a much smaller magnification of only 50 to 60 percent and thus would infer much larger changes in alternative policies in Colombia.

We have abstracted from aggregate fluctuations and asymmetric policy changes in our analysis. The movements in the real exchange rate and the business cycle certainly influenced trade in Colombia. It is feasible to extend our analysis to include asymmetries in trade policies and aggregate shocks.

\section{Data Appendix}

Exporter Dynamic statistics: To measure how export intensity and continuation prob-

abilities of starters at different horizons compare to the unconditional moments, we define export intensity for firm i as

$$
e_{i t}=\frac{\operatorname{exports}_{i t}}{\text { sales }_{i t}}
$$

An exporter dummy is then defined as

$$
d_{i t}^{e x}= \begin{cases}0 & e x s_{i t}<0.0001 \\ 1 & e x s_{i t} \geq 0.0001\end{cases}
$$

Starter and stopper dummies are defined as

$$
\begin{aligned}
& d_{i t}^{\text {starter }}=\left\{\begin{array}{cc}
0 & \text { otherwise } \\
1 & d_{i t-1}^{e x}=0 \& d_{i t}^{e x}=1
\end{array}\right. \\
& d_{i t}^{\text {stopper }}=\left\{\begin{array}{cc}
0 & \text { otherwise } \\
1 & d_{i t}^{e x}=0 \& d_{i t+1}^{e x}=0
\end{array}\right.
\end{aligned}
$$


With these in hand, we run the following sets of regression

1. Marginal exporter premia/discount: To calculate the relative size of a the marginal exporters, i.e. starters and stoppers, we define a dummy as

$$
d_{i t}^{m}=\left\{\begin{array}{cc}
0 & \text { otherwise } \\
1 & d_{i t}^{s t a r t e r}=1 \text { or } d_{i t}^{\text {stopper }}
\end{array}\right.
$$

We then run a regression of

$$
x_{i t}=\alpha_{m} d_{i t}^{m}+\lambda d_{i t-k}^{\text {exporter }}+X_{i t}+\varepsilon_{i t},
$$

where $\mathrm{x}_{i t}$ is either $\log$ sales or $\log$ employment. We then report $\exp \left(\alpha_{m}\right)$ to get the relative size of the marginal exporter to an average exporter.

2. Export intensity dynamics come from a regression of

$\operatorname{exs}_{i t}=\alpha_{0}+\rho e x s_{i t-1}+\beta d_{i t}^{\text {starter }}+\sum_{k=0}^{n} \lambda_{k} d_{i t-k}^{\text {exporter }}+\sum_{k=0}^{n} \theta_{k} d_{i t+k}^{\text {stopper }}+\xi d_{i t}^{\text {stopper,starter }}+\eta \ln \left(e m p_{i t-1}\right)+X_{i t}+\varepsilon_{i t}$

I also include a separate dummy for firms that start and stop in the same year since the time aggregation problem for these guys is most extreme. Given the coefficients, we can then estimate a path for a continuing exporter. An advantage of this approach is that we can trace out the evolution of continuing exporters beyond our sample period.

3. Export participation - we run regression of export participation on

$$
d_{i t}=\alpha_{0}+\rho e x s_{i t-1}+\beta d_{i t}^{\text {starter }}+\sum_{k=0}^{n} \lambda_{k} d_{i t-k}^{\text {exporter }}+\chi d_{i t}^{\text {last } 2}+\xi d_{i t}^{\text {stopper,starter }}+\eta \ln \left(e m p_{i t-1}\right)+X_{i t}+\varepsilon_{i t}
$$

where $d_{i t}^{\text {last } 2}=1$ if a producer last exported in $\mathrm{t}-2$.

All regressions are done with year and industry fixed effects and robust standard errors clustered by plant.

Weighting. To explain aggregate exports, we should weight each plant in the regression by its sales in each year. 
To calibrate our model requires us to deal with two measurement issues related to small producers being under-represented in the Census and employment measures being a poor measure of the labor input. To deal with the first feature, we assume that there are many more plants with less than 10 employees that looked exactly like the plants in the sample. The assumption that these guys are representative may be strong since there is something that leads them to be in the sample and not the other producers.

To deal with the second feature, we created an efficiency until of labor. That is, I measured total labor payments per worker in the aggregate and then divided labor payments (salaries and benefits) by producers by this measure. This gives me a distribution of firms by efficiency units of labor which I used to discipline the model. In short, this approach says that a much larger share of employment is in the largest plants. An added advantage of this approach is that sales rises almost one for one with this measure of employment while with the body county it rose about $25 \%$ faster. This may reflect differences in hours worked or efficiency of workers.

Distortions: We use the following data to construct distortions

- Material costs $=\mathrm{ic}+$ import taxes ( $\mathrm{t} 2)$

- Labor costs $=$ salaries $(\mathrm{w} 7)+$ benefits $(\mathrm{w} 14)$

\section{References}

[1] Alessandria, George and Horag Choi, 2007. "Do Sunk Costs of Exporting Matter for Net Export Dynamics?" Quarterly Journal of Economics, 122(1), 289-336.

[2] — 2014a. "Establishment Heterogeneity, Exporter Dynamics, and the Effect of Trade Liberalization." Journal of International Economics.

[3] — , 2014b. "Do Falling Iceberg Costs Account for Recent US Export Growth?" Journal of International Economics.

[4] Alessandria, George and Horag Choi, 2015. "The Dynamics of the U.S. Trade Balance and the Real Exchange Rate: The J Curve and Trade Costs?" mimeo.

[5] — , and Ruhl, 2014. "Trade Adjustment Dynamics and the Welfare Gains from Trade" NBER WP 20663. 
[6] Baldwin, Richard and Paul Krugman, 1989. "Persistent Trade Effects of Large Exchange Rate Shocks," Quarterly Journal of Economics, 104(4), 821-854.

[7] Das, Sanghamitra, Mark Roberts, and James Tybout, 2007. "Market Entry Costs, Producer Heterogeneity, and Export Dynamics," Econometrica, 75(3), 837-873.

[8] Dixit, Avinash K., "Hysteresis, Import Penetration, and Exchange Rate Pass-Through," Quarterly Journal of Economics, CIV (1989a), 205-228.

[9] — , "Entry and Exit Decisions Under Uncertainty," Journal of Political Economy, XCVII (1989b), 620-638.

[10] Eaton, J., M. Eslava, C. J. Krizan, M. Kugler, and J. Tybout (2009): "A Search and Learning Model of Export Dynamics," mimeo.

[11] Eaton, J., M. Eslava, M. Kugler, and J. R. Tybout (2008): "Export Growth in Colombia: Firm-Level Evidence," in The Organization of Firms in a Global Economy, ed. by E. Helpman, D. Marin, and T. Verdier. Harvard University Press.

[12] Kohn, D., F. Leibovici, and M. Szkup (2015): "Financial Frictions and New Exporter Dynamics," International Economic Review.

[13] Krugman, P. (1980): "Scale Economies, Product Differentiation, and the Pattern of Trade," American Economic Review, 70(5), 950-959.

[14] Roberts, M. (1996) "Colombia, 1977-85: Producer Turnover, Margins, and Trade Exposure," in Mark J. Roberts and James R. Tybout (eds.), Industrial Evolution in Developing Countries: Micro Patterns of Turnover, Productivity, and Market Structure, Oxford University Press (1996), pp. 227-259.

[15] Roberts, Marks and James Tybout, 1997. "The Decision to Export in Colombia: An Empirical Model of Entry with Sunk Costs," American Economic Review, 87(4), 545564.

[16] Ruhl, K. J., and J. L. Willis (2008): "New Exporter Dynamics," mimeo, NYU Stern School of Business. 


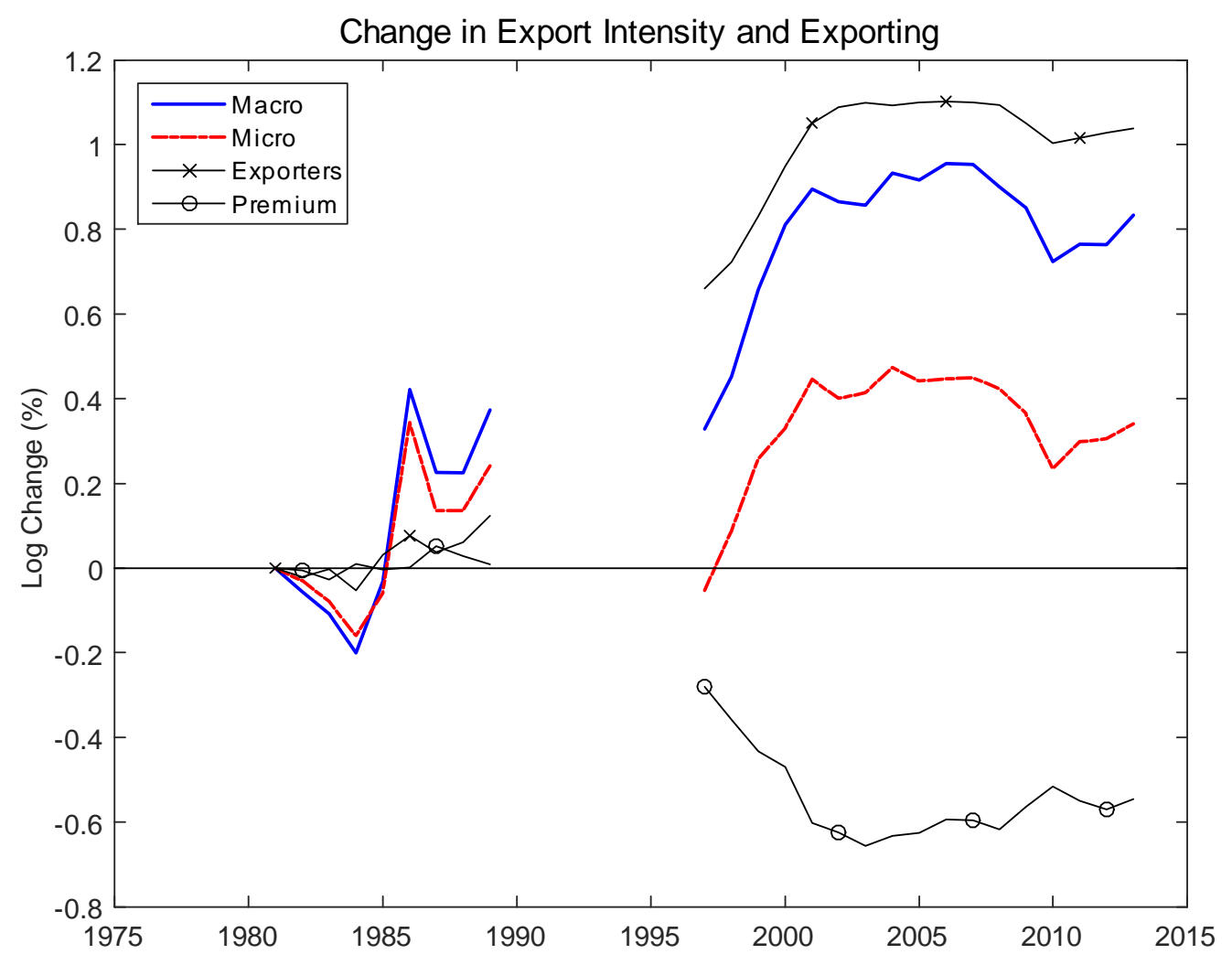

Dynamics of Exports and Exporter Characteristics 


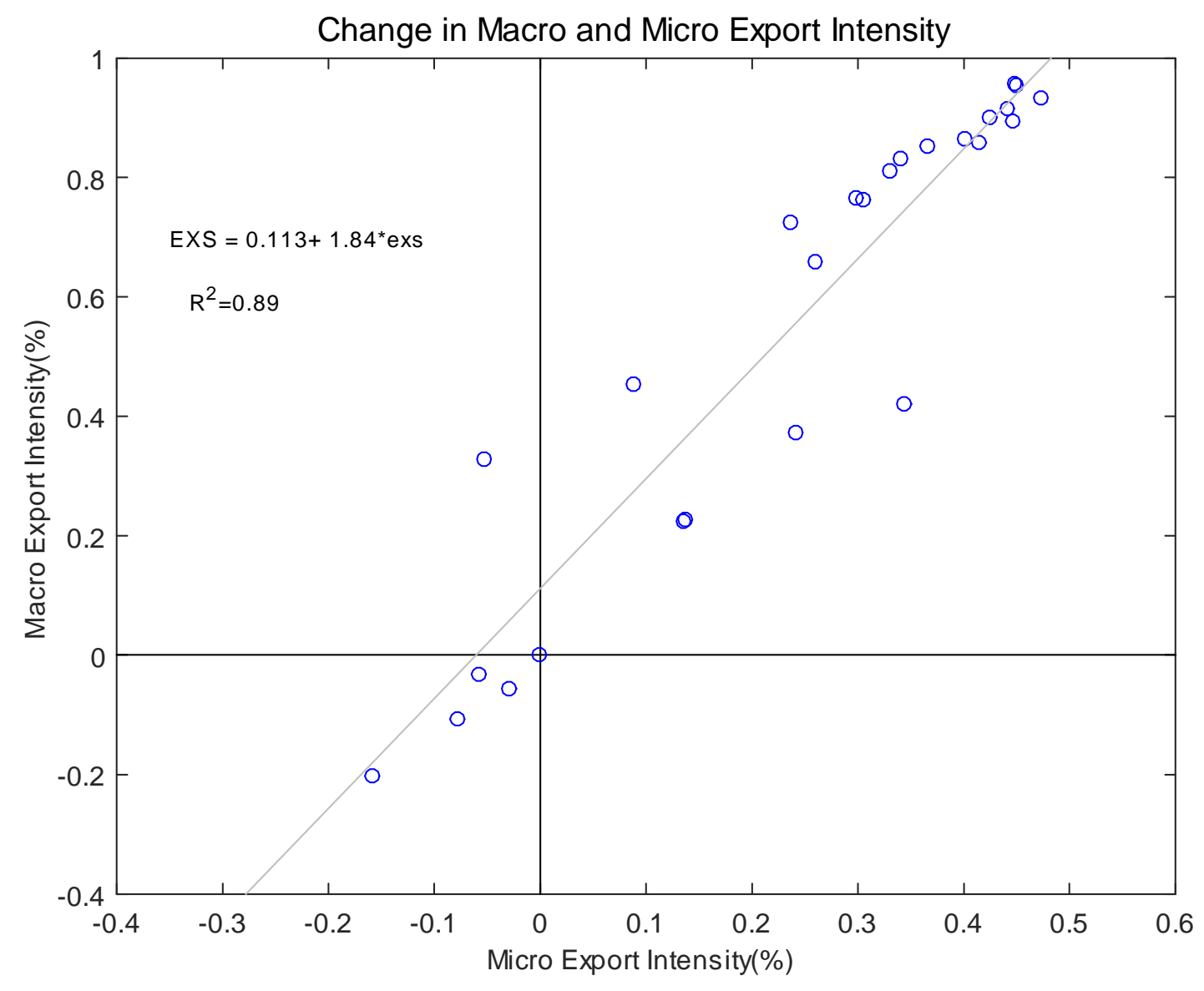

Change in Macro and Micro Export Intensity 

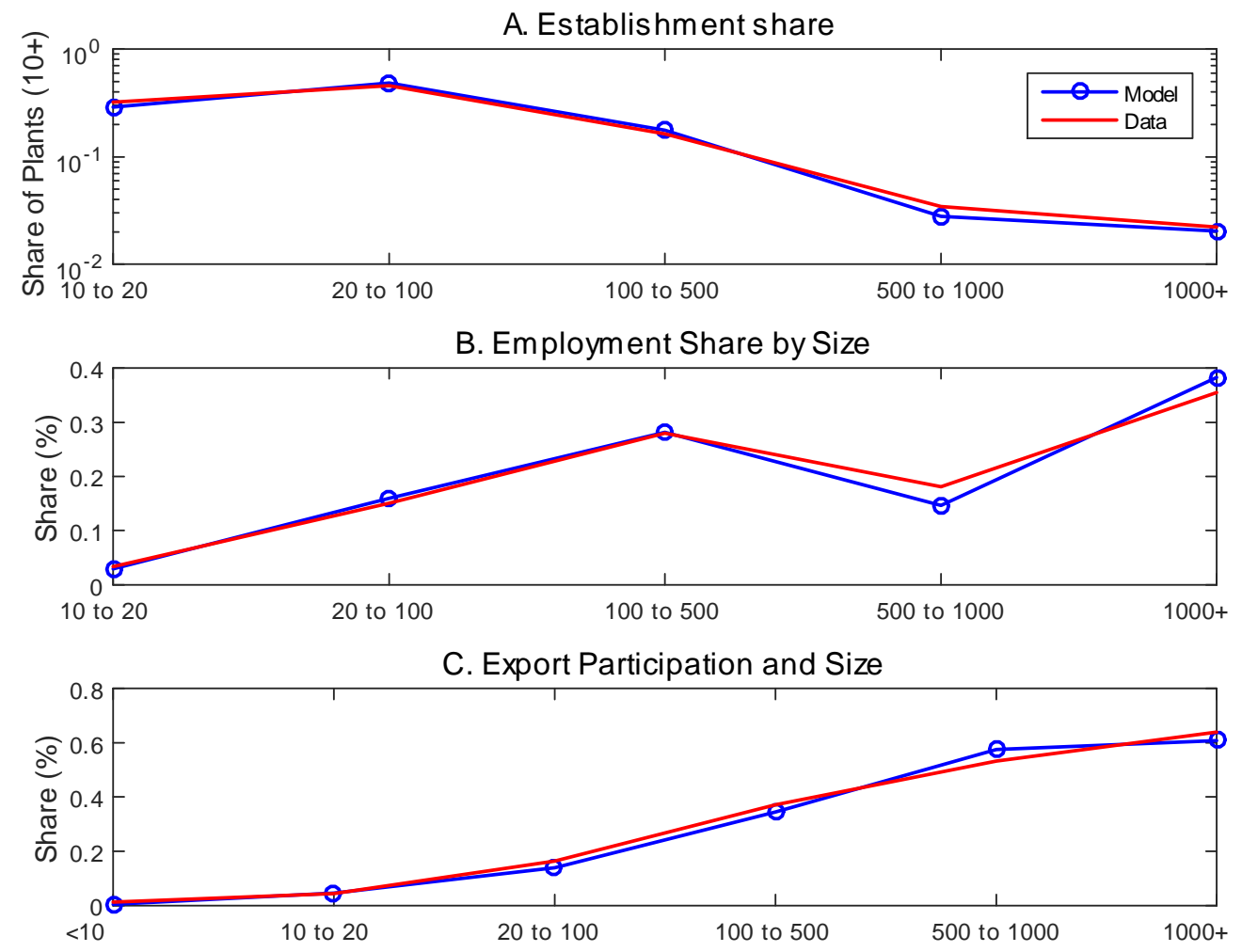

Figure 3: Producer Characteristics Model and Data (1981/82) 


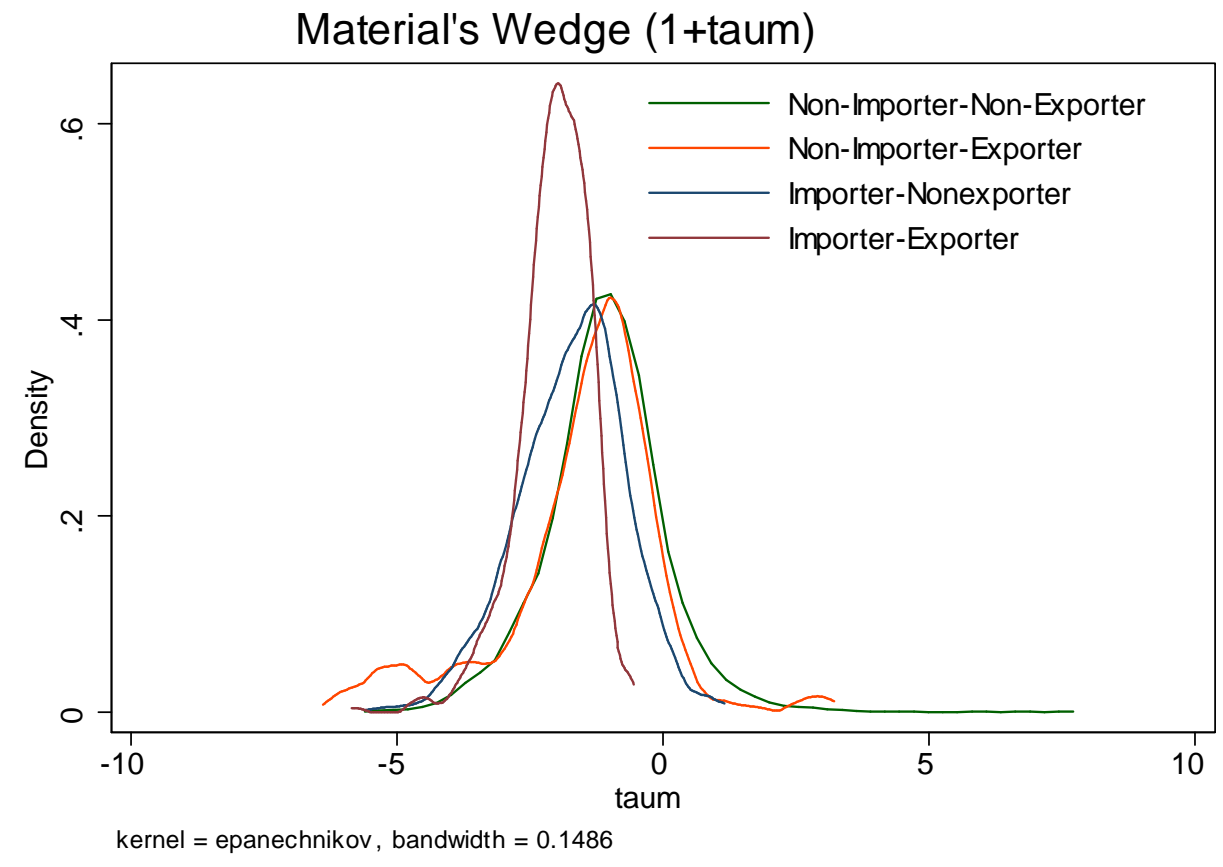

Figure 4: Materials Wedge 


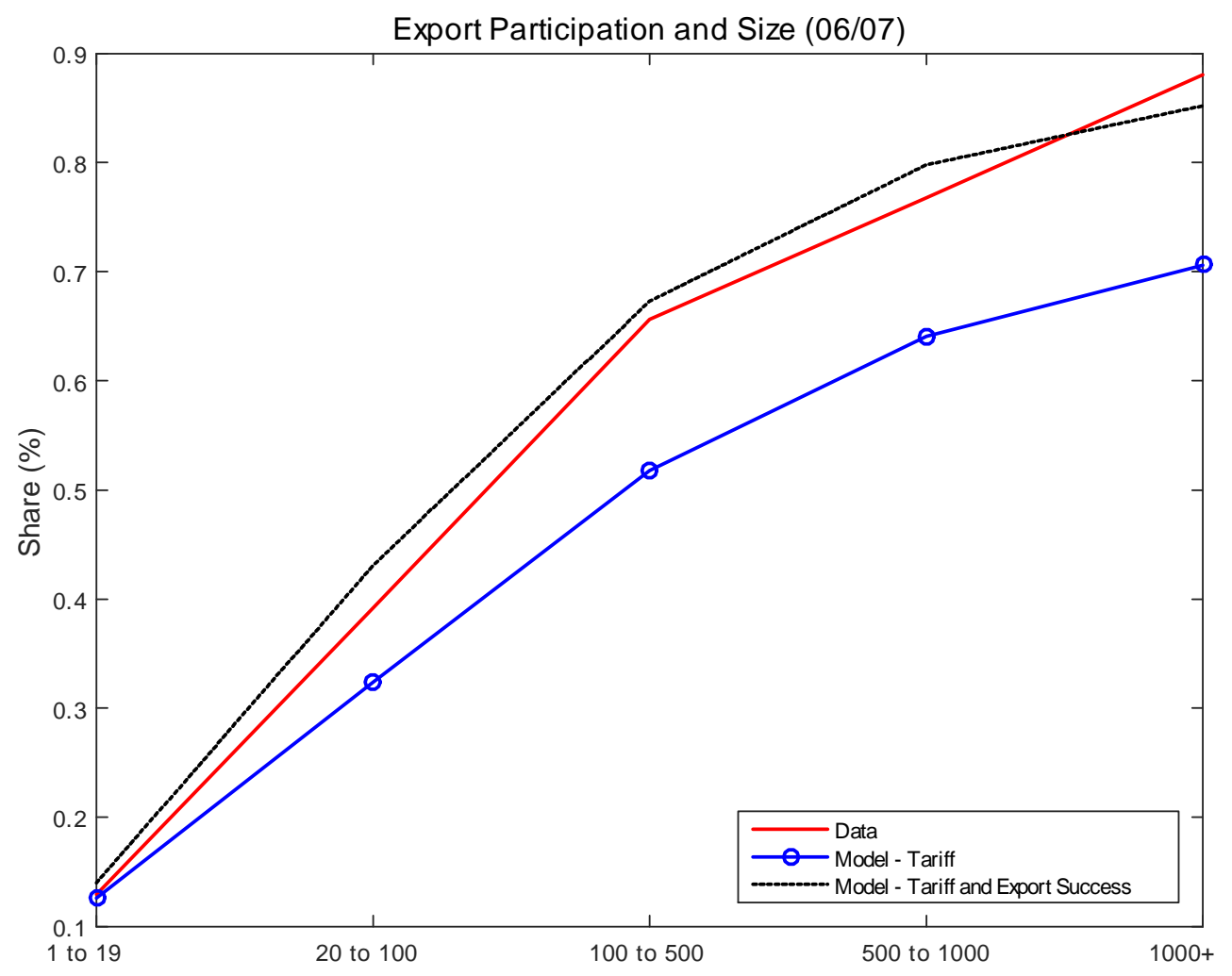

Figure 5:Export Participation in Data and Model by Size (2006/07) 

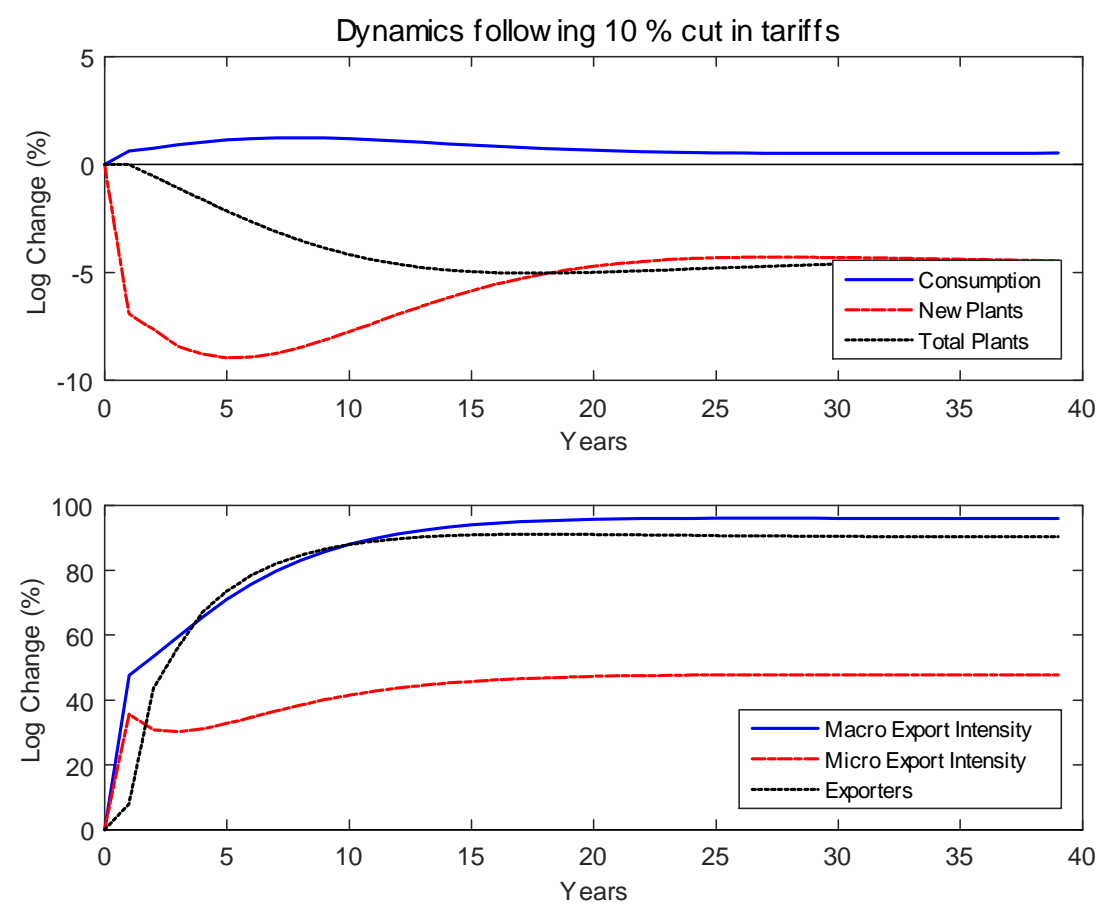

Figure 6: Dynamic Response to Change in tariffs and export success 


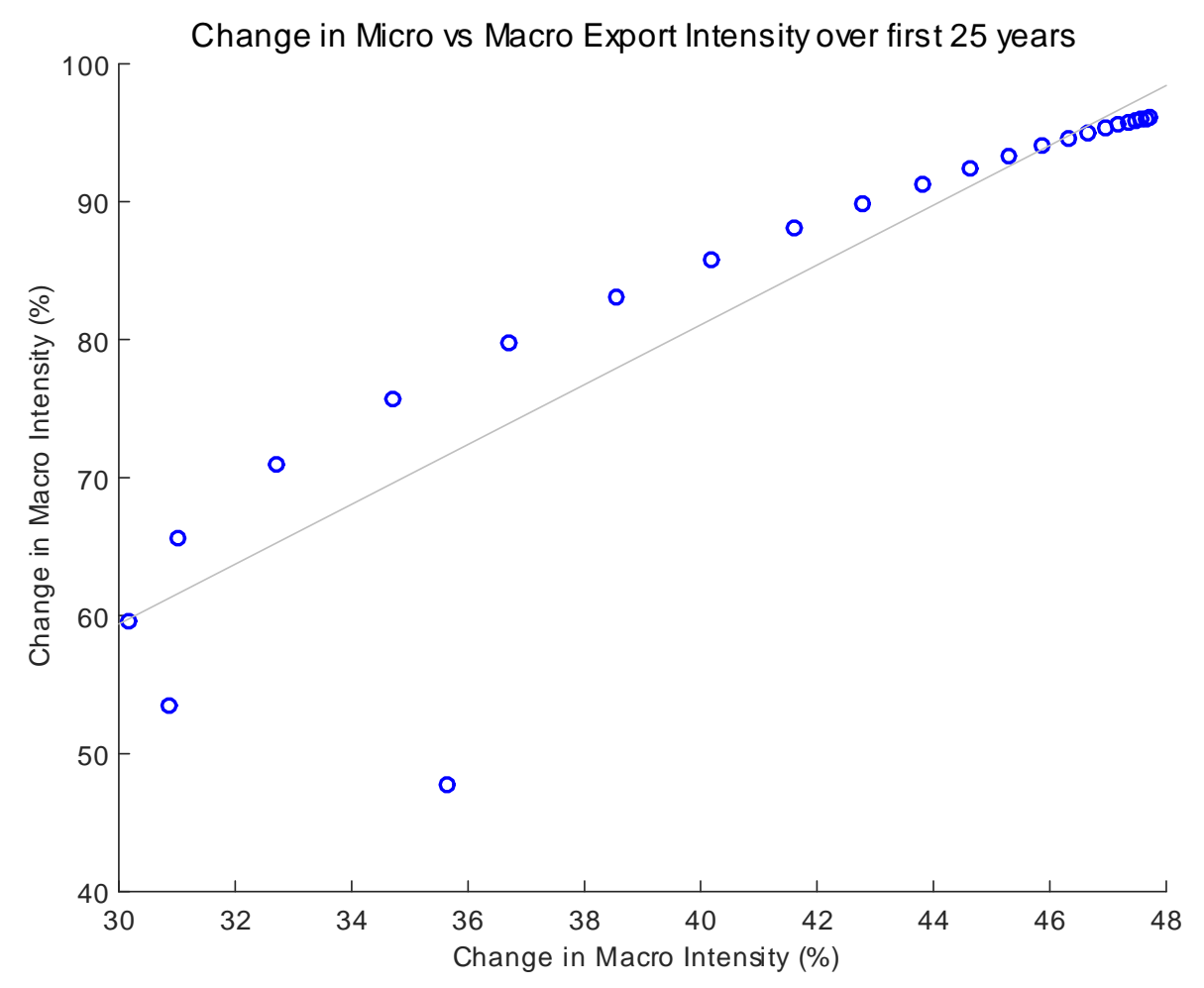

Figure 7: Micro and Macro Export Intensity in Model 
Table 1: Decomposition of Export Growth (relative to 81/82)

\begin{tabular}{rrrrr}
\hline \hline & EXS & exs & Participation & Premium \\
\hline $1988 / 89$ & 0.329 & 0.204 & 0.103 & 0.021 \\
$1997 / 98$ & 0.419 & 0.034 & 0.702 & -0.315 \\
$2006 / 07$ & 0.955 & 0.452 & 1.106 & -0.603 \\
$2012 / 13$ & 0.860 & 0.355 & 1.048 & -0.543 \\
\hline \hline
\end{tabular}

Table 2: Colombian Exporter Dynamics

\begin{tabular}{rrr}
\hline \hline & $81-89$ & $97-13$ \\
\hline Annual Participation & 17.6 & 13.1 \\
Annual Exports & 4.2 & 2.1 \\
& & \\
Marginal Exporter's Sales & 0.41 & 0.60 \\
$\frac{e x s_{1}}{e x s}$ & 0.46 & 0.42 \\
$\rho_{\text {exs }}$ & 0.94 & 0.94 \\
Yr avg & 11 & 13 \\
$\frac{e x s 20}{e x s}$ & 1.33 & 1.21 \\
Export Probability & & \\
Exporter & 0.90 & 0.83 \\
Starter & 0.66 & 0.56 \\
Last exported 2 years ago & 0.30 & 0.20 \\
\hline \hline
\end{tabular}

Table 3: Output Wedge

\begin{tabular}{lccccccc}
\hline \hline & tauy & tauy & tauy & tauy & tauy & tauy & tauy \\
\hline Inputs & $-0.23^{* * *}$ & & $-0.26^{* * *}$ & $-0.26^{* * *}$ & $-0.26^{* * *}$ & $-0.25^{* * *}$ & $-0.33^{* * *}$ \\
Exporter & & $-0.18^{* * *}$ & $0.15^{* * *}$ & $0.26^{* * *}$ & $0.25^{* * *}$ & $0.25^{* * *}$ & $0.19^{* * *}$ \\
Importer & & $-0.28^{* * *}$ & $0.15^{* * *}$ & $0.14^{* * *}$ & $0.22^{* * *}$ & $0.22^{* * *}$ & $0.16^{* * *}$ \\
Export Intensity & & & & $-0.50^{* * *}$ & $-0.49^{* * *}$ & $-0.50^{* * *}$ & $-0.44^{* * *}$ \\
Import share & & & & & $-0.24^{* * *}$ & $-0.25^{* * *}$ & $-0.27^{* * *}$ \\
Invent-Sales & & & & & & $0.04^{* * *}$ & \\
Inventory-BOY & & & & & & & $0.05^{* * *}$ \\
Inventory-EOY & & & & & & & $0.06^{* * *}$ \\
\hline $\mathrm{N}$ & $6.1 \mathrm{e}+04$ & $6.1 \mathrm{e}+04$ & $6.1 \mathrm{e}+04$ & $6.1 \mathrm{e}+04$ & $6.0 \mathrm{e}+04$ & $6.0 \mathrm{e}+04$ & $5.5 \mathrm{e}+04$ \\
r2_a & .54 & .36 & .55 & .55 & .56 & .56 & .59 \\
rmse & .54 & .63 & .53 & .53 & .52 & .52 & .5 \\
\hline \hline
\end{tabular}

Controls: age, industry, year, months 
Table 4: Input Wedge

\begin{tabular}{lcccccc}
\hline \hline & taum & taum & taum & taum & taum & taum \\
\hline Sales & $-0.28^{* * *}$ & & $-0.32^{* * *}$ & $-0.31^{* * *}$ & $-0.28^{* * *}$ & $-0.33^{* * *}$ \\
Exporter & & $-0.18^{* * *}$ & $0.23^{* * *}$ & $0.33^{* * *}$ & $0.29^{* * *}$ & $0.28^{* * *}$ \\
Importer & & $-0.39^{* * *}$ & $0.11^{* * *}$ & $0.22^{* * *}$ & $0.18^{* * *}$ & $0.19^{* * *}$ \\
Import Intensity & & & & $-0.32^{* * *}$ & $-0.35^{* * *}$ & $-0.34^{* * *}$ \\
Export Intensity & & & & $-0.50^{* * *}$ & $-0.43^{* * *}$ & $-0.43^{* * *}$ \\
Inventory Sales & & & & & & $0.07^{* * *}$ \\
Inventory-BOY & & & & & $0.04^{* * *}$ & \\
Inventory-EOY & & & & & $0.01^{* *}$ & \\
\hline $\mathrm{N}$ & 60853 & 60906 & 60853 & 60298 & 55440 & 55440 \\
$\mathrm{r} 2$ a & .41 & .3 & .41 & .44 & .48 & .39 \\
rmse & .85 & .92 & .84 & .8 & .73 & .8 \\
\hline \hline
\end{tabular}

Controls: age, industry, year, months 
Table 5: Model Parameters

\begin{tabular}{|c|c|c|c|}
\hline \multicolumn{4}{|c|}{ Common parameters } \\
\hline$\beta$ & $\sigma$ & $\delta$ & \\
\hline 0.96 & 1.0 & 0.10 & \\
\hline \multicolumn{4}{|c|}{ Model-specific parameters } \\
\hline & Benchmark & Sunk & Fixed \\
\hline$\theta$ & 5.00 & 5.00 & 5.00 \\
\hline$\alpha$ & 0.132 & 0.132 & 0.132 \\
\hline$\alpha_{m}$ & 0.810 & 0.810 & 0.810 \\
\hline$\lambda$ & 0.128 & 0.128 & 0.128 \\
\hline$n_{d 0}$ & 0.0226 & 0.0226 & 0.0226 \\
\hline$\rho_{z}$ & 0.90 & 0.90 & 0.90 \\
\hline$\sigma_{\varepsilon}$ & 0.975 & 0.851 & 0.851 \\
\hline$\mu_{E}$ & -1.31 & -1.31 & -1.31 \\
\hline$\theta f_{E}$ & 6.84 & 6.75 & 6.772 \\
\hline$f_{H} / f_{E}$ & 0.033 & 0.327 & 0.15 \\
\hline$f_{H} / f_{L}$ & 0.61 & 3.44 & 1 \\
\hline$\xi_{H}$ & 1.906 & 1.45 & 1.45 \\
\hline$\xi_{L}$ & 1.1014 & 1.45 & 1.45 \\
\hline$\rho_{\xi}$ & 0.925 & 0.5 & 0.5 \\
\hline$\eta$ & 0.1416 & 1 & 1 \\
\hline \multicolumn{4}{|c|}{ Overall Fit (RMSE) } \\
\hline Estab + Empl. & 1.73 & 3.97 & 3.95 \\
\hline Export & 2.66 & 13.43 & 14.9 \\
\hline \multicolumn{4}{|c|}{ Additional Implications } \\
\hline Macro Export Intensity & 5.5 & 5.5 & 5.5 \\
\hline Micro Export Intensity & 12.3 & 12.3 & 12.3 \\
\hline New Exporters & 19.0 & 19.1 & 40.4 \\
\hline New Exporter Exports & 4.2 & 19.6 & 27.9 \\
\hline Entrant Labor Share & 2.18 & 2.46 & 2.46 \\
\hline Shutdown Labor Share & 1.07 & 1.84 & 1.84 \\
\hline Entrants 5-year Survival Rate & 37.0 & 38.0 & 38.0 \\
\hline
\end{tabular}


Table 6: Export Growth: Model vs Data

\begin{tabular}{|c|c|c|c|c|c|c|}
\hline & Macro & Micro & Ratio & \multicolumn{2}{|c|}{ Intensive Margin } & Stopper Rate \\
\hline & & & & Tariff & Trade costs & \\
\hline Data $(06 / 07)$ & 95.5 & 45.2 & 2.12 & & & 15.5 \\
\hline Benchmark, & 74.3 & 47.0 & 1.59 & 40.4 & 6.6 & 17.2 \\
\hline Benchmark $\Delta \eta$ & 95.5 & 47.8 & 2.00 & 40.4 & 7.4 & 16.6 \\
\hline Benchmark $\Delta f_{1}$ & 95.7 & 54.1 & 1.76 & 40.4 & 13.7 & 4.0 \\
\hline Benchmark $\Delta f_{0}$ & 94.6 & 49.0 & 1.93 & 40.4 & 8.6 & 38.8 \\
\hline Benchmark $\Delta f_{0}=\Delta f_{1}$ & 95.8 & 53.2 & 1.80 & 40.4 & 12.8 & 8.9 \\
\hline Benchmark $\Delta \xi$ & 95.5 & 61.3 & 1.56 & 40.4 & 20.9 & 16.7 \\
\hline Sunk Cost & 66.1 & 40.4 & 1.64 & 40.4 & 0 & 16.0 \\
\hline Fixed Cost & 64.4 & 40.4 & 1.59 & 40.4 & 0 & 36.0 \\
\hline
\end{tabular}

